SATI-Q: una experiencia local en Quality Benchmarking. Rev Argent Ter Intensiva. 2016; 33(4):1-3.

9. Kochanek PM, Carney N, Adelson PD, Ashwal S, et al. Guidelines for the acute medical management of severe traumatic brain injury in infants, children, and adolescents-second edition. Pediatr Crit Care Med. 2012; 13(Suppl 1):S1-82.

10. Horvat CM, Mtaweh H, Bell MJ. Management of the Pediatric Neurocritical Care Patient. Semin Neurol. 2016; 36(6):492-501.

11. Argentina. Secretaría de Salud de la Nación. Listado Establecimientos de Salud Asentados en el Registro Federal (REFES). [Accessed on: October 17 $\left.{ }^{\text {th }}, 2019\right]$.
Available at:https: / / datos.gob.ar/ dataset/ salud-listadoestablecimientos-salud-asentados-registro-federal-refes.

12. Argentina. Dirección deEstadísticas eInformación en Salud. Egresos de Establecimientos Oficiales por Diagnóstico: año 2013. 2015;11(4). [Accessed on: February 25 $5^{\text {th }}, 2019$ ]. Available at: http: / / www.deis.msal.gov.ar/wp-content / uploads/2016/07/Serie11Nro14.pdf.

13. Starr S. Survey research: we can do better. J Med Libr Assoc. 2012; 100(1):1-2.

14. Rosenberg DI, Moss MM, American Academy of Pediatrics Section on Critical Care, American Academy of Pediatrics Committee on Hospital Care. Guidelines and levels of care for pediatric intensive care units. Pediatrics. 2004; 114(4):1114-25.

\title{
Survey on knowledge, prescription habits, and management of fever among pediatricians at a children's hospital
}

\author{
Norberto D. Giglio, M.D. ${ }^{a}$, Natalia Talamona, M.D. ${ }^{a}$, Vanesa E. Castellano, M.D. ${ }^{a}$, Liliana Sabbaj, M.D. ${ }^{b}$ and \\ Ángela Gentile, M.D. ${ }^{a}$
}

\begin{abstract}
Introduction. There are discrepancies in relation to pediatricians' approach to fever. Our objective was to describe the knowledge, prescription habits, and drug and non-drug treatment indications for fever among physicians at a children's hospital in the Autonomous City of Buenos Aires.

Material and methods. Observational, descriptive, analytical, cross-sectional study conducted at Hospital de Niños Ricardo Gutiérrez in 2018.
\end{abstract}

a. Department of Health Protection and Promotion, Area of Epidemiology.

b. Outpatient Facilities of the Department of Pediatrics. Hospital de Niños Ricardo Gutiérrez, Autonomous City of Buenos Aires, Argentina.

E-mail address:

Norberto D. Giglio, M.D.: norbergiglio@gmail.com

Funding:

This study was funded by an unrestricted grant awarded by Sanofi Aventis, which was used in relation to the survey materials, and an educational grant awarded to Natalia Talamona, M.D.

Conflict of interest:

The authors V. Castellano, N. Giglio, L. Sabbaj, and Á. Gentile did not receive any fee for this project. V. Castellano, N. Giglio, and Á. Gentile were lecturers in a conference sponsored by Sanofi Aventis in the context of a National Conference of the Argentine Society of Pediatrics.

Received: 4-23-2019

Accepted: 10-28-2019
Results. A total of 100 surveys were completed: $37 \%$ of pediatricians always indicated physical methods, whereas $54 \%$ did so occasionally; $68 \%$ alternated antipyretic agents, while $72 \%$ considered this practice increased the risk for toxicity; and $32 \%$ stated that early management reduced the risk for seizures. Conclusions. Pediatricians have prescription habits and indicate drug and non-drug treatments for fever that have demonstrated little effectiveness.

Key words: fever, antipyretic agents, health care staff, surveys and questionnaires.

http: / / dx.doi.org/10.5546/ aap.2020.eng.209

To cite: Giglio ND, Talamona N, Castellano V, Sabbaj L, Gentile Á. Survey on knowledge, prescription habits, and management of fever among pediatricians at a children's hospital. Arch Argent Pediatr 2020;118(3):209-213.

\section{INTRODUCTION}

Although there are several recommendations for the management of fever, ${ }^{1,2}$ different studies have described discrepancies in relation to pediatricians' approach. ${ }^{3-6}$ Anxiety and uncertainty regarding the potential severity of fever, or fever phobia, lead parents to make repeated consultations or request alternating or combined antipyretic agents.

These conditions may explain the discrepancies described in management. The objective of this study was to describe the knowledge, prescription habits, and drug 
and non-drug treatment indications for fever among physicians at a children's hospital in the Autonomous City of Buenos Aires.

\section{METHODOLOGY}

This was an observational, descriptive, analytical, cross-sectional study conducted between August and October 2018 with a selfadministered, voluntary survey. The study included pediatricians of Hospital de Niños Ricardo Gutiérrez, located in the Autonomous City of Buenos Aires, who provided outpatient care as part of their routine practice, at a public or private level. Pediatricians who participated in the protocol development and implementation and pediatric medical residents were excluded.

Pediatricians were selected by convenience sampling based on their availability. The questionnaire's form and contents were validated with a pilot test in 10 pediatricians; demographic data, risk/benefit perceptions of fever management, and prescription habits in relation to antipyretic agents were collected (Annex).
Results were presented based on a descriptive analysis that included mean and median values for quantitative outcome measures, and percentages for categorical outcome measures.

This study was approved by the Research and Teaching Committee and the Research Ethics Committee of Hospital de Niños Dr. Ricardo Gutiérrez. In all cases, a written informed consent was obtained.

\section{RESULTS}

One hundred surveys were administered. All pediatricians agreed to participate; their median age was 35 years old (interquartile range [IQR]: 31-47); and $84 \%$ of them were females. The mean number of years of professional practice was 9.8 years, and the median, 5 years (IQR: $1.5-18$ ).

In relation to fever diagnosis, $83 \%(95 \%$ confidence interval [CI]: 74.6-89.4) of pediatricians considered a temperature of $38^{\circ} \mathrm{C}$ or higher as fever; $15 \%$ (95\% CI: 8.9-23.2), between $37.5^{\circ} \mathrm{C}$ and $37.9^{\circ} \mathrm{C}$; and $2 \%(95 \% \mathrm{CI}: 0.3-6.4), 37^{\circ} \mathrm{C}$. In relation to the temperature value considered

TABLE 1. Prescription of antipyretic agents by age of patients and alternating habits, $\%$ (95\% CI)

\begin{tabular}{lll}
\hline Pediatricians, $\mathbf{n}=\mathbf{1 0 0}$ & & Percentage (95\% CI) \\
\hline Prescribed antipyretic agent* & $\geq 6$ months old: & $100(97-100)$ \\
& Ibuprofen & $49(39.3-58.8)$ \\
& Dipyrone & $18(11.4-26.4)$ \\
Alternating antipyretic agents & Acetaminophen & $10097-100)$ \\
& $<6$ months old: & $68(58.4-76.6)$ \\
Type of alternating antipyretic agents $(\mathrm{n}=68)$ & Acetaminophen & $32(23.4-41.6)$ \\
& Yes/ sometimes & $39(26.8-48.8)$ \\
& No & $38(28.9-47.8)$
\end{tabular}

${ }^{*}$ Multiple-choice question.

TABLE 2. Indication of antipyretic agents by temperature value, \% (95\% CI)

\begin{tabular}{lccc}
\hline Temperature & $38-38.5^{\circ} \mathrm{C}$ & $38.6-39{ }^{\circ} \mathrm{C}$ & $>39{ }^{\circ} \mathrm{C}$ \\
\hline Acetaminophen & $30(21.6-39.5)^{\star *}$ & $13(7.4-20.7)$ & $10(5.2-17.1)$ \\
Ibuprofen & $88(80.5-93.3)$ & $93(86.6-96.9)$ & $79(70.2-86.1)$ \\
Dipyrone & $10(5.2-17.1)$ & $24(16.4-33.09)^{* *}$ & $43(33.5-52.8)^{* *}$ \\
\hline
\end{tabular}

Ibuprofen has been the most commonly prescribed antipyretic agent at the three temperature levels shown in the table.

** It is worth noting that, out of all pediatricians who prescribed acetaminophen, the number of those who preferred it for lower temperatures was statistically significant in relation to those who prescribed it for higher temperatures. Out of all pediatricians who prescribed dipyrone, the number of those who preferred it for higher temperatures was statistically significantly higher than those who prescribed it for lower temperatures. 
for the prescription of an antipyretic agent, $75 \%$ (95\% CI: 65.8-82.7) of pediatricians reported that they indicated it if the average temperature was $38{ }^{\circ} \mathrm{C} ; 15 \%$ (95\% CI: 8.9-23.2), as of $37.8{ }^{\circ} \mathrm{C} ; 6 \%$ (95\% CI: $2.5-12)$, as of $37.5{ }^{\circ} \mathrm{C} ; 2 \%$ (95\% CI: $\left.0.3-6.4\right)$, $37.9^{\circ} \mathrm{C}$; and the remaining $2 \%$ (95\% CI: $0.3-6.4$ ), as of $37.7^{\circ} \mathrm{C}$. Thirty-seven percent (95\% CI: 28-46.8) of pediatricians stated that they always indicated physical methods, like baths or wet cloths, to lower the fever, whereas $54 \%$ (95\% CI: 44.1-63.6) indicated them occasionally.

Table 1 describes the prescription patterns for antipyretic agents, including details of the drug prescribed by age and alternating and/or combination habits. Table 2 shows the prescription patterns for antipyretic agents based on fever values. Table 3 describes therapeutic goals and pediatricians' beliefs regarding the management of fever.

In relation to complications from fever, $24 \%$ (95\% CI: 16.4-33.1) answered that seizures could occur; $41 \%$ (95\% CI: 31.7-50.9), dehydration; and $45 \%$ (95\% CI: 35.5-54.8), no damage. When asked about the risk for febrile seizures, $32 \%$ (95\% CI: 23.4-41.6) indicated that an early treatment reduced the risk of having them; $63 \%$ (95\% CI: 53.2-72) that it did not, and $5 \%$ (95\% CI: 1.8-10.7) did not know.

An analysis was done to establish if there were differences in the number of years after pediatricians had graduated and the use of alternating antipyretic agents, and no significant differences were observed between 10 or more years of practice and alternating antipyretic agents (odds ratio [OR]: 0.96;
$95 \%$ CI: 0.35-2.5); or between 20 or more years of practice and alternating antipyretic agents (OR: 0.86; $95 \%$ CI: 0.21-2.9).

\section{DISCUSSION}

Our results showed that a relevant proportion of pediatricians manage fever based on risk practices and perceptions that are different from those included in most treatment recommendations. For example, among the $68 \%$ of pediatricians who indicate alternating antipyretic agents, more than one-third use drugs with the same mechanism of action and toxicity. So, why do most pediatricians continue alternating antipyretic agents if this practice has already been described in our setting and warnings have been issued about its toxicity risks? $?^{3,7,8}$

Such behavior may be explained by certain issues, such as the disagreement between the recommendations made by different associations and organizations, as described in the review by Chiappini et al., ${ }^{5}$ as well as the perception of a low risk for toxicity associated with alternating drugs among pediatricians. For example, some publications by the American Academy of Pediatrics Committee on Drugs do not contraindicate this practice based on the claim that there is not enough evidence to refute or accept it. ${ }^{9}$ In this regard, the English National Institute for Health and Care Excellence ${ }^{1}$ and the Australian Department of Public Health ${ }^{10}$ recommend alternating drugs but only when

TABLE 3. Goals of treatment with antipyretic agents and considerations regarding alternating antipyretic agents

\begin{tabular}{lll}
\hline Pediatricians, $\mathbf{n}=\mathbf{1 0 0}$ & & Percentage \\
\hline Goal of treatment with antipyretic agents & & $94 \%$ (95\% CI: 89.9-97.5) \\
& Improve comfort. & $50 \%$ (95\% CI: 40.3-60.2) \\
Does combining or alternating antipyretic agents & Lower temperature. & $21 \%$ (95\% CI: 13.9-29.8) \\
increase the risk for adverse events (toxicity)? & Prevent complications. & $72 \%$ (95\% CI: 62.6-80.1) \\
& No. & $19 \%$ (95\% CI: 12.2-27.6) \\
Do you think that alternating antipyretic agents & I do not know. & $8 \%$ (95\% CI: 3.8-14.6) \\
helps to calm down parents' anxiety? & Yes. & $78 \%$ (95\% CI: 69-85.3) \\
& No. & $6 \%$ (95\% CI: 2.47-12.1) \\
Do you think that prescribing antibiotics helps & I do not know. & $16 \%$ (95\% CI: 9.7-24.2) \\
to calm down parents' anxiety? & Yes. & $64 \%$ (95\% CI: 54.2-73) \\
& No. & $20 \%$ (95\% CI: 13-28.7) \\
\hline
\end{tabular}

* Multiple-choice question. 
monotherapy fails, in order to improve the patient's general condition. Finally, the American Academy of Family Physicians and the Italian, South African, and New South Wales guidelines do no recommend this practice due to a potential toxicity risk. For this reason, most authors agree that there is not enough evidence to promote alternating drugs and recommend monotherapy as a first-line treatment. ${ }^{5,9}$

On the contrary, given the low incidence of severe adverse events associated with antipyretic agents, a priori, pediatricians may consider that alternating drugs is a low risk prescription. Anyway, this potential low risk assessment is not enough, possibly because the objective of most studies about anti-fever agents is to assess their effectiveness and, therefore, lack enough power to detect uncommon, severe adverse events related to alternating drugs.

In relation to the use of physical methods and their questionable effectiveness, our results are also similar to those published by other authors. For example, Melamud et al. ${ }^{3}$ have described, in their questionnaire, a $96 \%$ use; Chiappini et al., ${ }^{11}$ showed that $78.5 \%$ of pediatricians indicated physical methods; and García Puga et al., ${ }^{4}$ that $93.6 \%$ recommended a bath or cold cloths. Straface et al. ${ }^{12}$ have described that $47 \%$ of pediatricians use cold cloths.

Although establishing which factors may predispose pediatricians to continue indicating physical methods was not an objective of this study, this is possibly due to the low risk of this practice, a lack of knowledge about current recommendations or the requests made by parents, so as to reduce their anxiety. In relation to the perception of the risks of fever, it has been demonstrated that antipyretic agents are not useful to prevent febrile seizures. Approximately $32 \%$ of pediatricians stated that febrile seizures could be prevented, which may also justify medication overuse. Other authors used the same question and found greater proportions of health care providers who had the same perception. ${ }^{6,13,14}$ Finally, some of these fever management strategies characterized as risky or ineffective may be influenced by parents' anxiety regarding their fevered child.

In relation to the preferences when prescribing antipyretic agents, out of all pediatricians who indicated acetaminophen, the number of those who preferred it for lower temperatures was statistically significant in relation to those who prescribed it for higher temperatures. Out of all pediatricians who prescribed dipyrone, the number of those who preferred it for higher temperatures was statistically significantly higher than those who prescribed it for lower temperatures. The preference for dipyrone in the case of a high temperature may be warranted by the fact that, in clinical trials, it maintained a normal temperature for longer. ${ }^{15}$ The prescription pattern for ibuprofen did not show a clear trend in relation to the temperature value, and it was the most commonly used antipyretic agent. The latter results were different from those observed by Straface et al., ${ }^{12}$ where acetaminophen was the most commonly used antipyretic agent.

Lastly, there is a clear difference in the prescription pattern for these drugs in infants younger than 6 months old, for whom only acetaminophen is prescribed [Ministry of Health, National Drug, Food and Technology Administration of Argentina (Administración Nacional de Medicamentos, Alimentos y Tecnología Médica, ANMAT). Provision No. 5306 (2017)]. This behavior may be related to the package inserts of the most commonly used drugs in Argentina, which state that ibuprofen safety has not been established in infants younger than 6 months old and that acetaminophen can be used from birth [Ministry of Health, (ANMAT), Provision No. 1459 (2017)].

Establishing associations between the factors conditioning the prescription habits described here was not an objective of this study. In any case, our findings propose the development of future studies to confirm or refute our hypotheses, for example, a study on the use of drugs to establish associations between prescription habits and associated factors.

\section{CONCLUSIONS}

According to our study, pediatricians have prescription habits and indicate drug and nondrug treatments for fever that have demonstrated little effectiveness.

\section{REFERENCES}

1. National Institute for Health and Care Excellence (NICE). Feverin under 5s: assessment and initial management. 2017. [Accessed on: March 1 $\left.{ }^{\text {st }}, 2019\right]$. Available at: guidance.nice. org.uk/cg160.

2. Bruno M, Ellis A, Ferolla M. De Cristofano A, et al. Consenso para el uso adecuado de antibióticos en el niño menor de 36 meses con fiebre sin foco de infección evidente. Arch Argent Pediatr. 2017; 115(Supl 2):S27-37.

3. Melamud A, Suwezda A, Matamoros, Ringuelet L. Indicación de antitérmicos por médicos pediatras. Internet como modalidad de recolección de datos. Arch Argent Pediatr. 2008; 106(5):404-8. 
4. García Puga JM, Garrido Torrecillas FJ, Hernández Morillas D, Castillo Díaz L, et al. Análisis del conocimiento y manejo de la fiebre por parte de pediatras y residentes en relación a un proceso asistencial establecido. Rev Pediatr Aten Primaria. 2012; 14(54):115-26.

5. Chiappini E, Bortone B, Galli L, De Martino M. Guidelines for the symptomatic management of fever in children: systematic review of the literature and quality appraisal with AGREE II. BMJ Open. 2017; 7(7):e015404.

6. Martins M, Abecasis F. Healthcare professionals approach pediatric fever significantly different ways and fever phobia is not just limited to parents. Acta Paediatr. 2016; 105(7):829-33.

7. Mayoral CE, Marino RV, Rosenfeld W, Greensher J. Alternating antipyretics: Is this an alternative? Pediatrics. 2000; 105(5):1009-12.

8. Heubi JE, Barbacci MB, Zimmerman HJ. Therapeutic misadventures with acetaminophen: Hepatoxicity after multiple doses in children. J Pediatr. 1998; 132(1):22-7.

9. Wong T, Stang A, Ganshorn H, Hartling L, et al. Combined and alternating paracetamol and ibuprofen therapy for febrile children. Evid Based Child Health. 2014; 9(3):675-729.

10. South Australian Child Health Clinical Network. Fever without a focus in infants and children excluding the newborn.2013. [Accessedon:October28 $8^{\text {th }}$,2019]. Availableat: https: / / www.sahealth.sa.gov.au/wps/wcm/ connect/ 81 2ad70040d041b4972cbf40b897efc8/Fever+without+Focus Apr2015.pdf?MOD=AJPERES\&CACHEID=ROOTWORK SPACE-812ad70040d041b4972cbf40b897efc8-mOXZyOF.

11. Chiappini E, Parretti A, Becherucci P, Pierattelli M, et al. Parental and medical knowledge and management of fever in Italian pre-school children. BMC Pediatr. 2012; 12:97.

12. Straface R, Balco $R$, Magariños $M$. Rueda $M$, et al. Conocimientos, creencias y conductas de padres y pediatras frente al niño febril de 1 a 24 meses de edad. Arch. Arg. Pediatr. 2001;99(6):1-18.

13. Dong L, Jin J, Lu Y, Jiang L, et al. Fever phobia: a comparison survey between caregivers in the inpatient ward and caregivers at the outpatient department in a children's hospital in China. BMC Pediatr. 2015; 15:163.

14. Piñeiro Pérez R, García Montalvo J, Sanz González $\mathrm{P}$, Falomir Carrasco R, et al. Fiebre-fobia nosocomial: unmiedocontagioso. Acta Pediatr Esp. 2017; 75(9-10):88-95.

15. Wong A, Sibbald A, Ferrero F, Plager M, et al. Antipyretic effects of dipyrone versus ibuprofen versus acetaminophen in children: results of a multinational, randomized, modified double-blind study. Clin Pediatr (Phila). 2001; 40(6):313-24. 


\section{ANNEX \\ ANONYMOUS SURVEY}

1. Sex: 1. F. 2. M.

2. Age:

3. How many years ago did you finish your residency program?

4. What temperature do you consider fever?

5. Do you use antipyretic agents at a specific temperature? Which one?

6. Do you indicate physical methods to lower temperature?
1. Always.
2. Sometimes.
3. Never.

7. Physical method(s) used:

1. A cloth with alcohol.

4. A bath with cold water.

2. A cloth with water.

5. Other:

8. What antipyretic agent do you prescribe to your patients, based on your preferences?

\begin{tabular}{|l|l|l|}
\hline & Younger than 6 months old & As of 6 months old \\
\hline Acetaminophen & & \\
\hline Ibuprofen & & \\
\hline Dipyrone & & \\
\hline Other & & \\
\hline
\end{tabular}

9. What antipyretic agent do you prescribe to your patients, based on your preferences and according to temperature values?

\begin{tabular}{|l|l|l|l|}
\hline & $38-38.5^{\circ} \mathrm{C}$ & $38.5-39^{\circ} \mathrm{C}$ & More than $39^{\circ} \mathrm{C}$ \\
\hline Acetaminophen & & & \\
\hline Ibuprofen & & & \\
\hline Dipyrone & & & \\
\hline Other & & & \\
\hline
\end{tabular}

10. What dosing interval do you indicate?

11. Do you use alternating antipyretic agents (at intervals between them) in your fevered patients?
1. Yes.
2. No.
3. Sometimes.

12. Which antipyretic agents do you most often alternate (1 or more)?
1. Acetaminophen/dipyrone.
2. Ibuprofen/acetaminophen.
3. Ibuprofen/dipyrone.
4. Other:

13. Do you think that alternating antipyretic agents helps to calm down parents' anxiety?
1. Yes.
2. No.
3. I do not know.

14. Do you think that prescribing antibiotics helps to calm down parents' anxiety?
1. Yes.
2. No.
3. I do not know.

15. Does combining or alternating antipyretic agents increase the risk for adverse events (toxicity)?
1. Yes.
2. No.
3. I do not know.

16. Does early treatment reduce the risk for febrile seizures?
1. Yes.
2. No.
3. I do not know.

17. What is your goal when prescribing antipyretic agents? (You may choose more than one option):
1. Lower temperature.
2. Prevent complications of fever.
3. Improve patient comfort.
4. I do not know.

18. What are the damages caused by fever? (You may choose more than one option):
1. Brain damage.
2. Seizures.
3. Death.
4. Dehydration.
5. None.
6. I do not know. 